\title{
Efficient, effective, and equitable e-minutes
}

More and more people are avoiding eye contact when volunteers are sought to take minutes at staff or departmental meetings, and who can blame them? Recording and disseminating the enormous amount of information that should be shared regularly among library staff members has hecome a Herculean task.

The task becomes more critical every day, where the quality of internal communication has a tremendous effect on the quality of service. Breaking the task into small, manageable pieces ensures the consistent, regular exchange of information among library staff members which, in turn, results in the best possible service to patrons.

While, according to Robert's Rules of Order, the responsibility for taking minutes at formal meetings must be taken by the secretary or recording secretary. responsibility for recording minutes of informal meetings can be shared by the entire group. All participants arrive at the meeting with information to share, ques- tions to ask, or problems to discuss. (These items can be typed and saved in an e-mail message to be added to or edited later.) Each member of the group assumes responsibility for recording discussions and decisions related to items that he or she introduces during the meeting.

After the meeting, the participant records only the portions of the meeting he or she initiated and e-mails them to a designated individual who simply cuts and pastes all input and sends one final document to the entire group.

This simple process encourages active involvement; assures that issues important to each indiviclual are adclressed, documented, and acted upon; allows all participants (both full-and part-time and those who are unable to attend all or part of a meeting) to stay well-informed; and provides casy-to-access records that can be saved electronically and referenced when needed-CPatricia Weaver, Saint Joseph s University. Philadelpbia: e-mail: pueaver@sju.edu or have been clirectors of academic libraries. Details and an application form are on the Web at http://is.gseis.ucla.edu/ seniorfellows/. Send nominations and applications to Beverly P. Lynch, director, Senior
Fellows Program, Graduate School of Education \& Information Studies, UCLA, 3045 Moore Hall, Mailbox 95121, Los Angeles, CA 90095 1521; phone: (310) 206-4294; fax: (310) 2066293; e-mail: bplynch@ucla.edu.

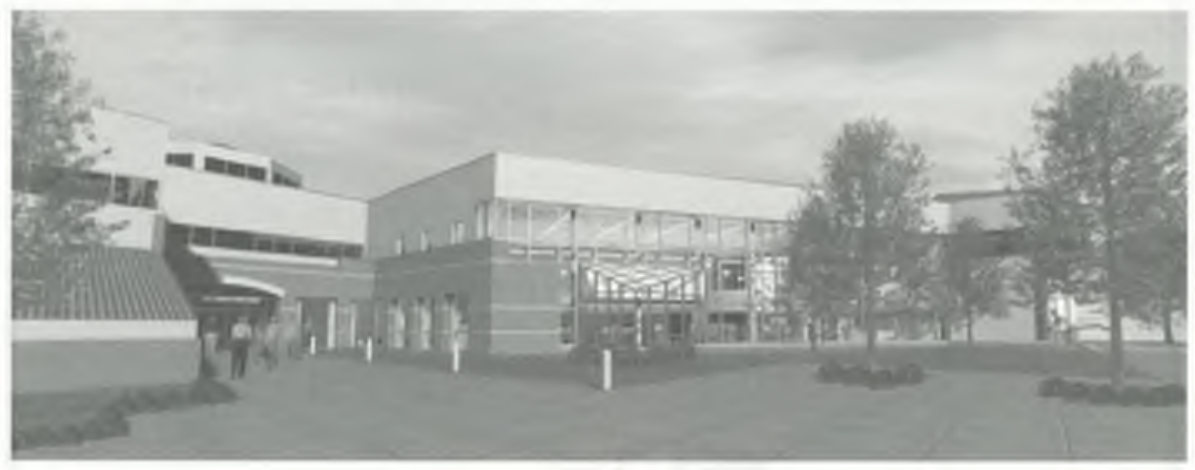

A representation of the new Information Technology Center at Linn State Technical College, located in rural central Missouri. The building will include a 12,000 square foot new library. The library plans to move into the new facility (which was designed by Pellham-Phillips-Hageman) in March 2001. 